\title{
Curso de especialização em Ensino de Geociências: vinte anos de experiências
}

\author{
Oscar Braz Mendonza Negrão \\ Instituto de Geociências - Unicamp \\ Campinas (SP) \\ oscar@ige.unicamp.br
}

\begin{abstract}
EXPERTISE COURSE IN EARTH SCIENCES TEACHING: TWENTY YEARS OF EXPERIENCE - This is a historic account of a course of expertise in Earth Sciences Teaching, developed in the Institute of Geosciences of Unicamp, which adopted an innovative model in terms of theory-practice relationship in teachers' continuing education. The course has been structured in four stages. First, the participants were engaged in planning the teaching activities; then, they applied these plans in classrooms and finally evaluated the overall trial. The previous work of the participant in his/her original institution set the starting point to the theoretical in-depth study, and also the goals to be attained. Finally a monograph was written as a final report to be evaluated by the professors. For some participants the application of first teaching plans fails. Among the reasons for this it can be stated that during some experiences the relationship between practice and theory did not follow the participant former intentions. So, the experience makes them able to critically improve their teaching plans for further developments. Citation: Negrão 0.B.M. 2014. Curso de Especialização para professores de Geociências. Terræ Didatica, 10(3):178-190. http://www.ige.unicamp.br/terraedidatica/.
\end{abstract}

KEYWORDS: Permanent education for professors; Earth Science teaching.

RESUMO Este artigo resgata a história de um curso de especialização em Ensino de Geociências, oferecido no Instituto de Geociências da Unicamp, que adotou um modelo inovador no que tange à relação teoria-prática na formação continuada de professores. O Curso em questão foi estruturado em quatro fases, nas quais o professor participante desenvolveu atividades de planejamento de ensino, aplicação desse planejamento, avaliação do conjunto da experiência e elaboração de monografia. O trabalho pedagógico (prática) do participante na própria instituição de origem constituiu o ponto de partida para seu aprofundamento teórico e também a meta a ser atingida, na forma de trabalho renovado. Entretanto, a aplicação dos planos de ensino revela que nem sempre houve adequação nas relações entre os procedimentos de ensino e as novas concepções, isto é, entre prática e teoria. A constatação, análise e avaliação dessa inadequação propiciam ao participante elaboração de planejamento mais aperfeiçoado.

PALAVRAS CHAVE: Formação continuada de professores; ensino de Geociências. 


\section{Introdução}

O curso de especialização em Ensino de Geociências para professores tem uma história de vinte anos, de 1979 a 1998. Foi aplicado nove vezes, atingindo mais de uma centena de professores de instituições públicas e privadas de ensino superior do País, principalmente geólogos, geógrafos, biólogos e engenheiros.

Antes de proceder à descrição e análise desse curso cabe relatar alguns antecedentes, e mesmo eventos ocorridos durante o período em que foi oferecido, visando sua contextualização.

No Brasil, os primeiros cursos de graduação em Geologia foram criados na década de 1950. A demanda por geólogos, então reprimida, levou a uma estrutura eminentemente técnico-científica desses cursos e a ofertas de emprego bem remunerado nas empresas. Em decorrência, o interesse dos geólogos pelo magistério no nível superior esteve tradicionalmente aquém da disponibilidade de vagas nessa atividade, concentrando-se nos cursos de Geologia e abrindo espaço nos demais cursos de graduação para outros profissionais, principalmente geógrafos, naturalistas ou biólogos, e engenheiros, que passaram a ministrar também disciplinas de introdução à Geologia em instituições públicas e privadas.

A dimensão das deficiências no ensino de graduação em Geologia começou a ser percebida mediante pesquisas sobre mercado de trabalho que incluíram opiniões dos geólogos sobre o próprio curso de formação. Instalado no MEC em 1972, o Conselho Consultivo do Programa de Geociências (CCPG) firmou convênio com o Centro de Desenvolvimento e Planejamento Regional da Universidade Federal de Minas Gerais (Cedeplar/ UFMG) visando pesquisa de âmbito nacional sobre mercado de trabalho de geólogos e engenheiros de minas. Essa pesquisa, realizada em 1973, coletou dados de 444 geólogos e 152 engenheiros de minas, incluindo opiniões sobre os cursos de graduação.

Cerca de $31 \%$ dos respondentes consideraram seu curso bom ou ótimo, 48\% razoável e $21 \%$ sofrível ou péssimo. As principais justificativas para as opiniões desfavoráveis foram: falta de ensino prático $(31 \%)$, professores desatualizados $(16 \%)$ e cursos não adequados à realidade econômica do Brasil (10\%). (Souza 1974, p.110-111). As deficiências estão relacionadas em grande parte à falta de qualificação pedagógica dos professores naquela época.
No mesmo ano da pesquisa do Cedeplar (1973) teve início uma experiência de ensino na disciplina de Geologia Geral do Instituto de Geociências da Universidade de São Paulo (IG-USP) que envolveu, no seu decorrer, grande parte do corpo docente do Departamento de Geologia Geral, geólogos estagiários do Departamento, vários monitores alunos e cerca de três mil estudantes (Amaral 1981). Discordando de procedimentos da instituição, a equipe responsável pela experiência deixou a Universidade em 1978 (Amaral 2013, 2014).

Fora da Universidade, diversos participantes da experiência no IG-USP formaram grupo autônomo com o mesmo coordenador e conseguiram concretizar projetos de ensino e pesquisa juntando esforços com outras universidades e sociedades técnico-científicas, especialmente a Sociedade Brasileira de Geologia (SBG). Destacam-se curso na Universidade Federal do Pará (UFPA) e pesquisa, além de simpósios, em colaboração com a SBG.

Mediante acordo com o Departamento de Geologia da UFPA, o grupo ministrou curso de especialização em Ensino de Geologia visando capacitação de docentes universitários, em especial os do próprio Departamento. O curso foi realizado em 1979 em Belém e representou a experiência precursora das edições seguintes, promovidas pela Universidade Estadual de Campinas (Unicamp), e que se estenderiam até 1998.

Ainda em 1979, a SBG criou sua Comissão de Ensino, atribuindo-lhe como primeira atividade a realização de pesquisa-diagnóstico do ensino de graduação em Geologia no Brasil. A pesquisa foi realizada em 1980/81 com apoio da Secretaria de Ensino Superior do MEC (MEC/SESu). Denominada A Formação do Geólogo nas Universidades Brasileiras, a pesquisa abrangeu quatro populações distintas: (a) unidades Universitárias que mantinham cursos de graduação em Geologia; (b) professores dos cursos de graduação em Geologia; (c) alunos desses cursos; (d) profissionais geólogos atuando fora da Universidade.

A amostra de profissionais abrangeu 346 geólogos, vinculados a empresas públicas e privadas. Eles apontaram por principais deficiências dos cursos de graduação as seguintes: (a) curso mal estruturado e fora da realidade; (b) falta de condições materiais e de trabalhos de campo; (c) deficiências didáticas e falta de interação teoria-prática; (d) corpo docente de má qualidade. (Amaral et al. 1981, p.147).

As deficiências apontadas pelos profissionais geólogos nas pesquisas de Cedeplar e SBG se refe- 
rem principalmente aos professores. Comparando-se as opiniões da primeira pesquisa com a segunda, verifica-se, decorridos sete anos, a manutenção de todas as deficiências.

Os dados da pesquisa da SBG evidenciaram também marcantes divergências entre professores e alunos quanto à metodologia de ensino empregada nos cursos de Geologia (Amaral et al. 1981, p.181-182). As divergências tornaram-se públicas em memorável mesa redonda no XXXI Congresso Brasileiro de Geologia, em 1980. Uma das moções ali aprovadas propôs a realização de cursos de especialização em Ensino de Geociências, visando atender aos cursos de graduação em Geologia no País. Outra moção propôs simpósio para discussão do ensino de Geologia no Brasil, que efetivamente se concretizou no ano seguinte.

Realizado em Belo Horizonte, o primeiro Simpósio Nacional sobre o Ensino de Geologia no Brasil foi deliberativo com participação paritária nas votações. A discussão era aberta ao público, mas as votações restritas aos delegados representantes das associações profissionais de geólogos, das instituições que mantinham cursos de graduação em Geologia (representantes docentes) e dos centros ou diretórios acadêmicos dos alunos dos cursos (representantes discentes). Entre as conclusões desse simpósio destaca-se:

12. Existe a necessidade de se transformar o trabalho docente em diversos níveis, a saber: c) existe a necessidade dos professores de geologia possuírem uma formação psico-pedagógica. Sugere-se a criação de Centros para assessoramento pedagógico e formação de especialistas em educação na área de Geologia. d) a pós-graduação deve retomar um de seus objetivos originais, o de preparar efetivamente docentes para o magistério superior, e não se limitar a oferecer conteúdos distantes de uma prática educacional. (Sociedade Brasileira de Geologia 1982, p. 12)

O segundo Simpósio Nacional sobre o Ensino de Geologia no Brasil foi promovido em Salvador (BA) em 1982, durante o XXXII Congresso Brasileiro de Geologia (Sociedade Brasileira de Geologia 1983). Mantendo o mesmo processo decisório desenvolvido no I Simpósio, dedicou-se a um único tema: novo currículo mínimo para os cursos de Geologia. Embora uma proposta de novo currículo mínimo tenha sido elaborada, discutida e aprovada no evento, não obteve posteriormente o aval de instâncias educacionais superiores.
A pesquisa e eventos mencionados, entre outras atividades, prepararam o terreno para a contratação, em 1983, de alguns componentes do referido grupo autônomo de ensino pelo Instituto de Geociências da UNICAMP, resultando na criação da Área de Educação Aplicada às Geociências (AEAG).

Em 1984 a AEAG ofereceu pela primeira vez o curso de especialização em Ensino de Geociências (CE), baseando-se na experiência do curso de Belém. A partir daí o CE foi oferecido a cada dois anos, exceto em 1988, dedicado à avaliação do curso e na edição de 1995, quando foi promovido pela Universidade Estadual de Feira de Santana, atuando a AEAG apenas como colaboradora.

Desde a primeira edição, em 1984, o CE contou sistematicamente com a colaboração do então Departamento de Metodologia do Ensino (DEME), atual Departamento de Ensino e Práticas Culturais (DEPRAC) da Faculdade de Educação da Unicamp. Em 1988 a AEAG promoveu, com a colaboração do DEME, simpósio com o intuito de avaliar a relevância do $\mathrm{CE}$ quanto à influência na prática docente dos professores participantes. Foram avaliadas as edições de 1984 e 1986, ambas oferecidas na Unicamp. No que tange às limitações do curso identificadas pelo evento, a principal sugestão foi a seguinte:

Considerando que a ruptura pelo participante de concepções e práticas anteriores é pré-requisito básico para mudanças mais significativas nos planos de conteúdo e método, dever-se-á valorizar ainda mais o ponto de partida do processo, isto é, a prática pedagógica anterior do participante (Universidade Estadual de Campinas 1990, p. 173-174).

Esta e outras sugestões levaram à ampla reformulação do CE na década de 1990.

A edição do curso tomada neste artigo para descrição e análise é a de 1994, quando os principais elementos programáticos e metodológicos já estavam consolidados.

\section{Descrição e metodologia do curso}

A formação continuada de professores foi submetida a críticas severas na década de 1980. Amaral (1990), por exemplo, destacava, ao lado de outras características desses cursos, a separação de teoria e prática educacional e o treinamento do professor para a reprodução, dificultando o exercício de sua autonomia. E propunha que a atuação profissional do professor participante fosse tomada como ponto 
Tabela 1. Elenco de Disciplinas do Curso de Especialização em Ensino de Geociências (1994)

\begin{tabular}{|c|c|}
\hline $1^{\mathrm{a}}$ Fase (Janeiro-Fevereiro) & Carga Horária \\
\hline GA 301 - Educação e Ensino de Geociências no Brasil & 45 \\
\hline GA 303 - Tópicos Especiais de Geologia II - História da Geologia & 45 \\
\hline GA 304 - Teoria do Conhecimento Geológico & 45 \\
\hline $\begin{array}{l}\text { GA } 305 \text { - Tendências Pedagógicas no Ensino Superior de Geociências I-Ensino } \\
\text { Formal }\end{array}$ & 45 \\
\hline $\begin{array}{l}\text { GA } 306 \text { - Tendências Pedagógicas no Ensino Superior de Geociências II-Ensino } \\
\text { Não-Formal }\end{array}$ & 45 \\
\hline GA 302 - Tópicos Especiais de Geologia I & 45 \\
\hline $3^{\text {a }}$ Fase (julho) & \\
\hline GA 309 - Avaliação do Ensino Superior em Geociências & 45 \\
\hline GA 308 - Planejamento de Aprendizagem de Campo em Geologia & 45 \\
\hline GA 307 - Planejamento e Ensino de Geociências no $3^{\circ}$ Grau & 45 \\
\hline GA 310 - Seminários de Metodologia do Ensino em Geociências & 45 \\
\hline
\end{tabular}

de partida para aperfeiçoamento nos campos da teoria pedagógica e do conteúdo geológico.

Outros pesquisadores participaram dessa reflexão crítica, registrando-a posteriormente, a exemplo de Gouveia (1995), que resgatou três décadas de história da formação continuada de professores de Ciências. Nos cursos em questão o participante não pesquisava a realidade educacional a que estava vinculado. Sua prática pedagógica também não era levada em conta e seu papel reduzia-se a adaptar à própria realidade as novas propostas oferecidas.

A experiência desenvolvida no Curso de Especialização em Ensino de Geociências (CE) busca exatamente apoiar-se na prática profissional de seus participantes, visando conferir-lhes autonomia para aperfeiçoá-la. A atividade principal para atingir esse objetivo é o trabalho piloto, que consiste no planejamento e aplicação de uma unidade programática da disciplina ministrada pelo participante em sua instituição.

As atividades do CE são distribuídas em quatro fases. Em traços gerais, a $1^{\text {a }}$ Fase (janeiro-fevereiro) abrange disciplinas e planejamento do trabalho piloto. A segunda (março a junho), execução e análise do trabalho piloto. A $3^{\text {a }}$ Fase (julho) também abrange disciplinas, sendo que a primeira delas inicia com a avaliação do trabalho piloto realizado e a última é concluída com a reformulação completa do planejamento da disciplina ministrada pelo participante. A $4^{\mathrm{a}}$ Fase consiste na elaboração de monografia. A $1^{\text {a }}$ e a $3^{\mathrm{a}}$ fases, ambas com disciplinas presenciais concentradas, são realizadas na Unicamp, enquanto a $2^{\mathrm{a}}$ e a $4^{\mathrm{a}}$ fases são desenvolvidas autonomamente pelos participantes em seus locais de trabalho (Tab. 1).

A estratégia geral do curso consiste em promover alternância de prática e teoria começando pela prática. Na estrutura do CE equipara-se o termo prática à expressão trabalho pedagógico. Freitas (1991, p.10) admite que o trabalho pedagógico pode ser interpretado como referência ao trabalho do professor em sala de aula ou ao trabalho da escola, que inclui o trabalho do professor em sala de aula. Embora o CE propicie ao participante estabelecer relações do seu trabalho com a instituição educacional a que pertence e com a sociedade mais ampla, o objeto proposto para transformação é esse trabalho pedagógico mais restrito, em sala de aula.

Assim, no início do CE o participante debate e reflete sobre seu trabalho pedagógico (prática). A seguir, toma contato com a fundamentação teórica oferecida nas disciplinas da $1^{\mathrm{a}}$ Fase (teoria), confrontando-a com sua prática e, finalmente, aplica o resultado desse confronto no planejamento e execução do trabalho piloto (prática ou trabalho pedagógico).

Segundo Gouveia (1994, p. 19), a alternância entre prática e teoria no curso pode ser assim representada:

$\begin{array}{ccc}(\mathrm{A}) & (\mathrm{R}) & (\mathrm{A}) \\ \text { Ação } & \text { Reflexão } & \text { Ação } \\ \text { prática } & \text { confronto } & \text { prática }\end{array}$

Trabalho pedagógico prática-teoria Trabalho pedagógico

O ciclo se repete de forma incompleta na $3^{\mathrm{a}}$ Fase do curso: a prática (trabalho pedagógico) 
de referência é a execução do trabalho piloto, seguindo-se disciplinas (teoria) e terminando com o planejamento integral da disciplina ministrada pelo participante (trabalho final). A aplicação desse planejamento ocorrerá somente depois do curso concluído, daí o caráter incompleto do ciclo.

A edição do curso objeto de análise foi a de 1994. Na época, o currículo compreendia dez disciplinas, distribuídas nas férias escolares em janeiro-fevereiro e julho, todas obrigatórias e de mesma carga horária (Tab. 1). Nota-se, pelo código das disciplinas, que houve mudança na sequência proposta originalmente.

A organização das disciplinas busca acompanhar a do curso, no sentido de iniciar com o trabalho pedagógico (prática) do participante, que serve de acesso à fundamentação teórica, resultando no confronto prática-teoria. Uma vez atingida a re-elaboração teórica pelo participante, procede-se à atividade de retorno à prática, que permite não só o aperfeiçoamento da compreensão da teoria oferecida quanto a remodelação dessa prática.

Considerando que a divisão do curso em quatro fases distingue essencialmente os períodos de aula ( $1^{\mathrm{a}}$ e $3^{\mathrm{a}}$ fases) daqueles dedicados à execução do trabalho piloto ( $2^{a}$ Fase) e monografia ( $4^{a}$ Fase), propõe-se nova divisão em sete etapas visando detalhar as atividades: (1) Questionário preliminar e diagnóstico; (2) Disciplinas da 1ª Fase; (3) Planejamento do trabalho piloto; (4) Execução e análise do trabalho piloto; (5) Disciplinas da $3^{\mathrm{a} F a s e ; ~(6) ~}$ Planejamento do trabalho final; (7) Elaboração de monografia.

\section{Questionário preliminar e diagnóstico}

A intenção do questionário preliminar é que o participante reflita sobre sua prática (trabalho pedagógico), sistematizando-a e aperfeiçoando sua compreensão sobre ela. Essa reflexão tem início antes do curso, pois o professor inscrito no CE remete o questionário respondido como condição para sua matrícula. No início da primeira disciplina o questionário é retomado em grupos de trabalho e em debate geral, que constituem práticas de acesso à teoria oferecida na disciplina. Quanto ao diagnóstico, trata-se de atividade de retorno à prática (trabalho pedagógico), feita ao final da primeira disciplina à luz da fundamentação teórica nela oferecida. Trata-se de um novo debruçar no trabalho pedagógico. As concepções registradas no questionário preliminar, e no próprio diagnóstico, continuam sujeitas a mudanças na sequência de desenvolvimento do curso.

\section{Disciplinas da $1^{\text {a }}$ Fase}

Aproximação do trabalho pedagógico do participante com a fundamentação teórica é feita por meio de uma atividade prática inicial em cada disciplina. Se conseguir apropriar-se satisfatoriamente da teoria e confrontá-la com a prática anterior, ele poderá aplicar tal reflexão ao planejamento do trabalho piloto e, posteriormente, ao planejamento da disciplina que ministra em sua instituição.

\section{Planejamento do trabalho piloto}

O planejamento começa com o diagnóstico na primeira disciplina e continua a ser construído ao longo das demais disciplinas da $1^{\text {a }}$ Fase. Concluída esta fase, fica ainda sujeito a alterações pelo participante, que às vezes são muito significativas. A partir do início da elaboração do planejamento, o participante conta com a orientação de um dos docentes, a qual se prolonga até o final do curso.

\section{Execução $\mathrm{e}$ análise do trabalho piloto}

A aplicação pelo participante de uma proposta de ensino renovada em sua própria instituição permite-lhe desenvolver um trabalho pedagógico diferente do anterior e compará-los entre si. É a única atividade do CE que torna isso possível. Posteriormente, por ocasião de seminário no início da $3^{\text {a }}$ Fase, o trabalho piloto é novamente analisado e também avaliado, desta vez por colegas participantes e docentes do curso.

\section{Disciplinas da $3^{\mathrm{a}}$ Fase}

O trabalho piloto representa na $3^{\text {a }}$ Fase o mesmo que o questionário preliminar na primeira. $\mathrm{O}$ trabalho pedagógico do participante mudou e essa prática renovada torna-se a nova referência para reflexão e aprofundamento teórico ao longo dessas disciplinas.

\section{Planejamento do trabalho final}

Realizado na última disciplina do curso, abrange a reformulação completa da disciplina ministrada pelo participante. Apóia-se nas contribuições das diversas disciplinas do CE e no planejamento, execução, análise e avaliação do trabalho piloto. 


\section{Elaboração de monografia}

A estrutura proposta para a monografia busca recuperar a trajetória do participante desde o início do CE, incorporando desde suas expectativas em relação ao curso até o planejamento do trabalho final. Nas conclusões, o participante faz uma apreciação do conjunto dessa trajetória.

\section{Relação entre teoria e prática}

Entende-se por relação entre teoria e prática a articulação entre o trabalho pedagógico (prática) do participante e a fundamentação teórica oferecida no CE, bem como aos resultados dessa articulação, representados por re-elaboração teórica e consubstanciados: (a) no planejamento e aplicação do trabalho piloto pelo participante, realizados durante o curso; (b) no re-planejamento da disciplina ministrada pelo participante, aplicado depois do curso concluído.

O trabalho pedagógico do participante, sistematizado no questionário preliminar, constitui a prática a partir da qual se espera que ele se aproprie da fundamentação teórica oferecida nas diversas disciplinas do curso. Um dos participantes declarou:

\footnotetext{
O questionário preliminar da primeira disciplina foi o tempo todo retomado até a nível inconsciente, ou conscientemente o tempo todo. Não só na primeira disciplina, mas ao longo das demais. Era a minha prática, era a minha metodologia, minha concepção de ensino que ali estava e que foi sendo todo o tempo questionada.
}

Questionário preliminar e correspondente discussão cumprem, assim, o papel de inserir, na dinâmica do curso, o trabalho pedagógico (prática) do participante como objeto de análise e transformação.

A fundamentação teórica oferecida a seguir, pelas diversas disciplinas, propiciaria ao participante a compreensão de seu trabalho pedagógico. Segundo Vazquez (1990, p.234),

Como Marx adverte em sua Tese VIII sobre Feuerbach, há a prática e a compreensão dessa prática. Sem a sua compreensão, a prática tem sua racionalidade, mas esta permanece oculta. Ou seja, sua racionalidade não transparece diretamente, e sim apenas a quem tem olhos para ela. Assim, por exemplo, a prática experimental científica só é revelada para o homem de ciência que a pode ler conhecendo a linguagem conceitual correspondente.
Naturalmente, o participante já tem uma compreensão de sua prática, isto é, de seu trabalho pedagógico. Pode-se dizer que o CE lhe proporciona uma mudança nessa compreensão.

(...) nunca mais eu vou ter a compreensão que eu tinha antes, uma nova compreensão agora, do aluno, do conhecimento do aluno, de como é que esse conhecimento deve ser tratado, isso eu imagino que vai refletir de alguma forma (...) na minha prática...

Ao constatar uma nova compreensão de sua prática, o participante supõe que, em decorrência, tal prática será modificada. Tal interpretação evidencia que compreendeu o movimento de alternância de teoria e prática buscado pelo CE.

À medida que avança o planejamento do trabalho piloto, cresce a expectativa em relação à sua aplicação.

(...) vou ter que quebrar algumas coisas que estão fortes dentro de mim, da experiência que eu tenho de dez anos de usar da lousa, do giz e do aluno como expectador. Se eu tiver que mudar isso, teoricamente eu acho mais fácil, até pelo grande embasamento teórico que eu tive, agora passar isso para a prática vai ter que mexer com algumas mudanças internas aí do dia-a-dia.

O participante prevê dificuldades na execução do trabalho piloto, cujo planejamento está elaborando, em virtude da necessidade de mudanças de procedimentos já enraizados em seu trabalho pedagógico. $\mathrm{Na}$ concepção marxista,

A atividade propriamente humana só se verifica quando os atos dirigidos a um objeto para transformá-lo se iniciam com um resultado ideal, ou finalidade, e terminam com um resultado ou produto efetivo, real (Vazquez, 1990, p. 187).

Traduzindo para a situação do CE, o planejamento do trabalho piloto implica um resultado ideal, sendo portanto uma atividade humana incompleta. Somente com sua execução pode surgir um resultado real, completando essa atividade. $\mathrm{O}$ participante procede a essa execução na $2^{\mathrm{a}}$ Fase, completando a atividade iniciada no planejamento. Planejamento e execução do trabalho piloto constituem novo referencial prático para aprofundamento teórico do participante ao longo da $3^{\text {a }}$ Fase. Contudo, desta feita, a aplicação da re-elaboração teórica limitar-se-á ao planejamento da disciplina ministra- 
da por ele. Assim, o chamado trabalho final consiste de uma atividade humana incompleta.

Com efeito, o homem pode sentir a necessidade de novas atividades práticas transformadoras para as quais carece do necessário instrumental teórico. A teoria é determinada, nesse caso, por uma prática da qual ainda não pode nutrir-se efetivamente. Pois bem, que significa essa determinação através de algo que ainda não existe ou que só existe de modo ideal? É a determinação através daquilo que, anteriormente, chamamos de finalidade, antecipação ideal daquilo que, não existindo ainda, queremos que exista. (Vazquez 1990, p.232)

Portanto, os planejamentos de ensino elaborados pelo participante no curso podem ser entendidos comofinalidades, antecipações ideais. No âmbito do CE, a única atividade prática transformadora desenvolvida pelo participante na qualidade de professor é aquela iniciada pelo planejamento do trabalho piloto e terminada com sua execução.

A prática transformadora singular, representada pelo planejamento e execução do trabalho piloto, determina diferenças essenciais entre $1^{\mathrm{a}}$ e $3^{\mathrm{a}}$ Fase.

$\mathrm{Na} 1^{\text {a }}$ Fase, o trabalho pedagógico (prática) do participante é objeto de análise individual e coletiva à luz da fundamentação teórica, de modo que ele possa ir aperfeiçoando a compreensão dessa prática e, simultaneamente, planejando mudanças nela. Assim, a prática do participante constitui o referencial de partida, ficando sujeita a mudanças em seu planejamento e, em curto prazo, em sua execução, esta na $2^{\text {a }}$ Fase.

As atenções do participante se concentram, durante a $1^{\mathrm{a}}$ Fase, no aprofundamento teórico e no planejamento (antecipação ideal) do trabalho piloto, a ser executado em futuro imediato.

$\mathrm{Na} 3^{\mathrm{a}}$ Fase, o trabalho pedagógico submetido à análise individual e coletiva é prática transformadora, representada pelo planejamento e execução do trabalho piloto. A reflexão sobre a prática se faz não só à luz da fundamentação teórica das disciplinas em andamento, mas também daquelas ministradas na $1^{\text {a }}$ Fase. A esta altura, as atenções do participante se concentram na reflexão sobre uma atividade humana completa, planejada na $1^{\text {a }}$ Fase e executada na $2^{\text {a }}$ Fase, em passado recente.

Esquematicamente, a experiência do trabalho piloto (TP) distribui-se nas diferentes fases do curso da maneira:

\begin{tabular}{|c|c|c|}
\hline $\begin{array}{c}1^{\mathrm{a}} \text { FASE } \\
\text { Planejamento } \\
\text { do TP }\end{array}$ & $\begin{array}{c}2^{\mathrm{a}} \text { FASE } \\
\text { Aplicação do TP }\end{array}$ \\
Reflexão sobre a \\
Aplicação do TP
\end{tabular}

Em suma, enquanto a $1^{\text {a }}$ Fase dedica-se ao planejamento (antecipação ideal) do trabalho piloto, com os olhos voltados para sua execução (resultado efetivo) no futuro imediato, a $3^{\mathrm{a}}$ Fase propõe-se à reflexão sobre essa prática, então já executada no passado recente.

Verifica-se que o trabalho piloto pode ser considerado o núcleo do CE, em virtude da importância que lhe é atribuída na organização do curso e da influência que exerce nas relações entre teoria e prática.

\section{Reflexão sobre a prática}

(...) vontade de vir fazer o curso e voltar (...) para a minha cidade e passar o que eu vim buscar aqui (...) um produto, uma receita para mudar o sistema de ensino (...). E não foi isso que eu encontrei aqui. Encontrei caminho, processo, algumas orientações que deixam uma visão um pouco desembaçada...

É frequente que as expectativas do participante em relação ao curso se restrinjam a conhecimentos elaborados, que ele poderia aplicar diretamente em sua realidade educacional. Perante tais expectativas, a intenção de que ele tome seu trabalho pedagógico como ponto de partida para reflexão não se concretizará mediante a simples proposta de que o faça, sendo necessários instrumentos, debates e atividades para tanto. A discussão sobre o questionário preliminar, a elaboração de diagnóstico a partir desse questionário e a incumbência de planejamento do trabalho piloto levam o participante a manter acesa a reflexão sobre seu trabalho pedagógico durante a $1^{\text {a }}$ Fase.

(...) o curso como um todo me levou a refletir, então eu acho que a característica fundamental dele foi tentar situar cada um de nós dentro do seu contexto em primeiro lugar, (...) o que eu estou fazendo, como é que eu estou me comportando, como é meu trabalho docente e como trabalhar isso, foi uma reflexão da minha parte.

(...) uma das coisas mais interessantes é a reflexão forçada que a gente faz. É como se um rolo compressor estivesse espremendo a gente contra uma parede para fazer pensar em tudo aquilo que a gente vinha fazendo.

Segundo Gouveia (1995, p.254), “a pratica docente, refletida pelos próprios sujeitos, em todas as suas dimensões e articulações, é a fonte privile- 
giada - embora não a única - do novo conhecimento". Assim, a reflexão sobre a prática docente, ou, em outras palavras, sobre o trabalho pedagógico, pode assumir características de uma pesquisa. De acordo com Carvalho e Gil Pérez (1993, p. 15),

(...) ao se proporcionar aos professores a oportunidade de um trabalho coletivo de reflexão, debate e aprofundamento, suas produções podem aproximar-se aos resultados da comunidade científica. Trata- se, então, de orientar o trabalho de formação dos professores como uma pesquisa dirigida, contribuindo assim, de forma funcional e efetiva, para a transformação de sua concepções iniciais.

Trabalho coletivo de reflexão, debate e aprofundamento é proporcionado duas vezes pelo $\mathrm{CE}$, tomando por referência, na $1^{\text {a }}$ Fase, o trabalho pedagógico original e na $3^{\text {a }}$ Fase o trabalho pedagógico renovado do participante.

Ao analisar os modelos que orientam os cursos de formação de docentes, Santos (1995, p.26) afirma:

(...) ganha cada vez mais terreno, no campo de uma pedagogia crítica, a proposta de formação do profissional reflexivo, aquele que pensa-na-ação, interrogando-se sobre as alternativas possíveis para um determinado momento e avaliando os seus resultados. Nesta perspectiva, a atividade profissional alia-se à atividade de pesquisa e o professor passa a ser visto como um pesquisador-na-ação.

A oportunidade de o participante desempenhar esse papel de pesquisador-na-ação ocorre durante a execução do trabalho piloto. Nesse momento, o participante está preparado para pensar-na-ação, pois refletiu continuamente sobre o próprio trabalho pedagógico ao longo da $1^{\text {a }}$ Fase e consubstanciou tais reflexões no planejamento do trabalho piloto. Ao analisar a execução desse trabalho, um dos participantes também associa sua atividade docente à de pesquisa.

(...) na hora da aplicação do (trabalho) piloto foi um momento difícil, (...) mas deu oportunidade de você perceber que a sua prática pedagógica nunca mais seria a mesma (...). Você passava a fazer o seu trabalho mais como pesquisador (...). A gente acabou fazendo um trabalho de pesquisa no ensino, então valoriza sua atividade de ensino como uma atividade de pesquisa também.

A pesquisa realizada pelo participante em seu trabalho pedagógico se enquadra como pesquisa prática, na classificação proposta por Demo (1994, p.35).
Podemos, a título de sistematização, delinear pelo menos quatro gêneros de pesquisa (teórica, metodológica, empírica e prática), todos interligados. (...) O quarto gênero de pesquisa é a pesquisa prática, destinada a intervir diretamente na realidade, a teorizar práticas, a produzir alternativas concretas, a comprometer-se com soluções. Ao contrário do que muitos ainda pensam, não se faz boa prática sem teoria, método, empiria, o que determina a necessária volta permanente ao questionamento teórico, e vice-versa.

O participante se põe a teorizar práticas pelo menos na $1^{\mathrm{a}}$ e na $3^{\mathrm{a}}$ Fase do curso, nas quais são ministradas as disciplinas; produzir alternativas concretas ao elaborar os planejamentos dos trabalhos piloto e final; e intervir diretamente na realidade durante a aplicação do trabalho piloto. Adota, assim, a postura de pesquisador.

$\mathrm{Na} 3^{\mathrm{a}}$ Fase, o trabalho pedagógico renovado, representado pela execução do trabalho piloto, passa a ser o novo objeto de reflexão, produzindo-se em consequência novos conhecimentos. Assim, o participante tem a oportunidade de refletir sobre sua prática anterior ao curso durante a $1^{\mathrm{a}}$ Fase e sobre a prática renovada durante a $3^{\mathrm{a}}$ Fase. Ao final da $3^{\text {a }}$ Fase, a compreensão mais aguçada do trabalho pedagógico permite-lhe divisar com mais nitidez o caminho a ser seguido.

.... gente tem um arcabouço teórico para, nas tentativas e erros, conseguir avaliar melhor o que fez e o que está acertando, na verdade a gente ficava tentando no escuro, buscando, não sabendo o que estava fazendo.

A declaração ilustra exatamente a situação referida por Demo (1994) de que não se faz boa prática sem teoria e evidencia que esse participante está habilitado a fazer a leitura de sua prática. Fundamentado teoricamente, ele se sente mais seguro para intervir em sua realidade.

\section{Manutenção e mudança da prática}

O trabalho piloto compreende planejamento, aplicação e avaliação de um tema ou unidade programática da disciplina ministrada pelo participante. O planejamento pode incorporar mudanças de concepções educacionais, mas somente a aplicação revela em que medida as novas concepções se convertem ou não em procedimentos renovados de ensino.

No relato da aplicação de seu trabalho piloto, um participante afirma que o incremento à partici- 
pação do aluno no processo da própria aprendizagem contribuiu para o estabelecimento de relações entre teoria e prática.

O citado por Moreira (1994), sobre considerarmos o "cotidiano" dos alunos, seus conhecimentos, sua cultura e de respeitá-los, possibilitou um melhor aproveitamento das aulas, principalmente das práticas, pois (...) contribuíram muito com a vinculação teoria/prática. (...) Certamente as mudanças na relação professor- aluno foram a base para o bom andamento da disciplina. Esta relação é de fácil estabelecimento, pois só depende de nós.

O participante associa consideração aos conhecimentos dos alunos com o respeito a eles devido. Ou, inversamente, a desconsideração a tais conhecimentos seria uma forma de desrespeito. A real consideração pelo cotidiano do aluno como ponto de partida da aprendizagem implica o respeito a ele e à sua participação nessa aprendizagem.

O fato do novo padrão na relação professor-aluno ter contribuído em grande medida para a vinculação entre teoria e prática não quer dizer, porém, que essa vinculação seja sempre adequada. Esta assertiva tornar-se-á mais clara a partir de análise de algumas aulas do mesmo participante, comparando-se inicialmente suas reflexões depois de concluída a $1^{\text {a }}$ Fase com a descrição do seu primeiro dia de aula.

Após a (1 ${ }^{\text {a }}$ Fase) do CE passei a refletir (...) em preparar aulas mais dinâmicas, procurando auxiliar os alunos no desenvolvimento de uma visão crítica por meio de uma maior participação dos mesmos em sala de aula e da tentativa de colocá-los para refletir mais, devolvendo-lhes uma série de questões que tinham condições de resolver, mudando neste momento a postura anterior de responder sem hesitar a qualquer questionamento...

Sem planejamento prévio, (...) na aula da tarde (primeiro dia) decidi que deveríamos ir para o campo, não sabia o que iria acontecer. (...) (Para minha) surpresa, os interesses do grupo foram bastante homogêneos, pedi que observassem o local e começaram então as questões. Este solo não é profundo, tem muita areia, como o braquiária está assim (bem desenvolvido)? Começaram então a dizer que o proprietário deveria ter feito calagem, que o braquiária era novo, alguns ainda observaram que a erosão parecia não ser intensa. $\mathrm{O}$ interesse surgiu, aproveitei a oportunidade para mostrar a importância do conteúdo que iríamos trabalhar durante o semestre, falando principalmente da relação das rochas com os solos...

O primeiro depoimento revela intenções de promover o raciocínio dos alunos com base nas perguntas que eles mesmos formulassem. O segundo demonstra que as intenções se concretizam, pois o participante solicita que os alunos façam observações e depois aguarda o surgimento de perguntas e subsequentes reflexões e interpretações, mas esse tipo de relação com os alunos não é mantido. Conforme relata o participante, nas aulas seguintes mudam seus procedimentos.

Fomos ao campo, observamos uma rocha exposta sob solo, nesta aula pedi que eles coletassem amostras, identificassem, etiquetassem e entregassem no laboratório.(...) O passo seguinte dizia respeito à identificação da rocha, após as aulas sobre rochas (ígneas, metamórficas e sedimentares), pedi que identificassem suas amostras e, após as primeiras aulas sobre intemperismo, solicitei que respondessem se a amostra coletada estava alterada ou não e o porquê.

Note-se que, desta feita, a atividade inicial dos alunos é quase mecânica e o participante retorna de fato ao procedimento a que estava habituado, isto é, atividade prática de identificação das amostras de rocha depois das aulas que ensinam a classificá-las e prática com rochas alteradas depois das aulas que ensinam sobre sua alteração. Em outras palavras, a prática nada mais seria do que uma aplicação da teoria. Candau e Lelis (1989) afirmam que a redução da prática reflete a dicotomia teoria-prática, embora em sua forma mais branda, a visão associativa.

Já na visão associativa, teoria e prática são pólos separados mas não opostos. Na verdade, estão justapostos. O primado é da teoria. A prática deve ser uma aplicação da teoria. A prática propriamente não inventa, não cria, não introduz situações novas. A inovação vem sempre do pólo da teoria. A prática adquirirá relevância na medida em que for fiel aos parâmetros da teoria. Se há desvios, é a prática que sempre deve ser retificada para melhor corresponder às exigências teóricas (Candau e Lelis 1989, p.53).

$\mathrm{Na}$ atividade pedagógica, é bastante disseminada a precedência das aulas teóricas em relação às aulas práticas. Esse papel da prática como aplicação da teoria não traduziria uma relação adequada entre teoria e prática. De acordo com Demo (1995), um dos desafios cruciais a ser enfrentado para atingir qualidade na educação se resume no seguinte: 
A prática precisa ser reconhecida como fonte de conhecimento também, não como mera aplicação; para tanto, deve ser teorizada, no sentido de partir da realidade, analisá-la criticamente e voltar à realidade, já com projeto alternativo; significa dizer que escola e universidade precisam saber manejar o background dos alunos, a realidade em que estão inseridos, a história de que fazem parte; a prática deve ser curricular, stricto sensu (Demo 1995, p.63).

Em sintonia com a posição do autor, a primeira excursão promovida pelo participante constitui fonte de conhecimento. Contrariamente à posição do autor, a atividade prática inicial seguinte (segunda excursão) não constitui fonte de conhecimento significativa, reduzindo-se ao aprendizado de habilidades muito simples para clientela de nível superior. Os alunos não analisam as amostras coletadas, faltando assim uma prática, ao mesmo tempo relevante e compatível com a teoria, para ser teorizada. Tais procedimentos evidenciam que a simples participação do aluno em atividades didáticas não implica obrigatoriamente vinculação adequada entre teoria e prática.

O aumento de participação dos respectivos alunos em relação à prática docente anterior dos participantes ocorre na aplicação de todos os trabalhos-piloto, mas de modo geral falta nos relatos uma análise da qualidade da participação. Não obstante, há indícios de vínculos consistentes entre teoria e prática em registros de diferentes participantes, nos quais a prática do aluno constitui efetivamente o ponto de partida para a aprendizagem.

Procurava-se fazer que os próprios alunos, em pequenos grupos, preparassem, executassem, calculassem e interpretassem cada uma das práticas realizadas. Na condição de professor tentava, sempre que surgiam dúvidas, respondê-las com um novo questionamento. Este procedimento teve como objetivo procurar estimular o raciocínio dos alunos.

A aplicação do TP [trabalho piloto] foi iniciada em maio, tendo como ponto de partida a organização do seminário 'Geologia e Meio Ambiente', onde o objetivo principal seria a discussão de problemas ambientais de S. Gonçalo.(...) Os alunos se envolveram bastante com a pesquisa, produzindo sínteses de ótimo nível. Na discussão, que aconteceu quinze dias após a escolha dos temas, os alunos também mostraram interesse e boa capacidade para relacionar os problemas levantados a condicionantes técnicos, sociais, históricos, políticos etc.
Cada aluno descreveu e discutiu com os demais as suas observações, tentando sempre relacionar as modificações dos diferentes dados de campo. No final, sintetizaram as suas informações. Quando a representação gráfica finalizou, questionou-se o seu resultado. O que foi realizado? Neste momento, houve uma grande satisfação, até mesmo alegria por parte dos alunos quando descobriram que eles haviam mapeado uma dobra e não sabiam a teoria.

Nas diferentes situações acima, respectivamente práticas de laboratório, pesquisa de problemas ambientais e trabalho de campo, o aluno é impelido a caminhar com seus próprios recursos. Embora nas três situações o problema seja proposto pelo participante, ele atua na qualidade de orientador, oferecendo espaço amplo para o aluno construir conhecimento a partir da própria experiência. E o aluno atua na qualidade de pesquisador, tendo oportunidade de teorizar a prática, funcionando a prática como fonte de conhecimento. Note-se que o ponto de partida do aluno é sempre sua prática, experiência, conhecimentos prévios. Snyders (1988, p.107) defende que "o conhecimento científico guarda continuidade com nossa experiência comum", oferecendo evidências disso.

As ideias das pessoas e em particular dos alunos quando abordam a fisica permitem-lhes interpretar de um modo sensato um número considerável de fenômenos - a partir de observações ocasionais e de um sentido do provável (Snyders 1988, p.106).

Metade dos participantes, entretanto, optou por iniciar seu trabalho piloto com leitura e discussão de textos ou aula teórica, que, por vezes deixaram entrever, não se situavam em continuidade com a experiência do aluno. Um deles escolheu textos de história da ciência sobre origem e estrutura da Terra e verificou que "as ideias dos alunos sobre o interior da Terra eram as mesmas dos precursores". As ideias dos precursores sobre o interior da Terra admitem um núcleo incandescente, enquanto os cientistas modernos defendem que o núcleo seja constituído por uma parte externa líquida e outra interna sólida. A interpretação baseia-se na propagação de ondas sísmicas e admite que a Terra seja formada por camadas esféricas concêntricas, que foram denominadas crosta, manto e núcleo (externo e interno). Tal modelo é definido pela densidade e pelo estado físico da matéria, no caso sólido ou líquido. 
Snyders (1988) acredita que a história da ciência demonstra claramente que o novo conhecimento é ruptura com o conhecimento supostamente estabelecido.

Por toda uma parte dele próprio o conhecimento é ruptura com o conhecimento habitual. Pode-se perceber isso especialmente a partir da história das ciências, e é uma das razões pelas quais ela deveria representar um papel no ensino científico: há uma história das ciências, um progresso das ciências e as concepções novas foram arrancadas de viva luta das representações habituais que não tinham em si nada de insensato... (Snyders 1988, p.101).

A concepção do núcleo incandescente tinha por evidência a constatação, já pelos mineiros na Antiguidade, da elevação da temperatura com a profundidade nas áreas continentais, acreditando-se que fosse progressiva até o centro da Terra. A interpretação baseada na propagação das ondas sísmicas derrubou essa crença e implicou ruptura com o conhecimento então estabelecido. O mesmo se deu com os alunos, cujas ideias eram as mesmas dos precursores.

Mas provavelmente o participante não obteve o sucesso almejado, o que o levou a criticar o tema escolhido para seu trabalho piloto.

(...) os conhecimentos que o aluno traz estão muito mais próximos da realidade que vive do que do abstracionismo que tentamos impor. Em outras palavras, se quisermos que estes alunos aprendam efetivamente alguma coisa de Geologia, é necessário trabalhar inicialmente com os processos geológicos que ocorrem no presente e na região em que vivem e só depois partir para fenômenos mais abstratos. Analisado sob este ângulo, o tema do (meu) Trabalho Piloto, por mais positivos que tenham sido alguns resultados, não se adequa a um início de curso por não fazer parte do "cotidiano" do aluno, ou seja, por não pertencer ao domínio dos conhecimentos que este traz, tomando-se de difícil entendimento em um primeiro momento.

De fato, ao iniciar o programa com o estudo do interior da Terra, o participante deixa de promover uma reflexão do aluno sobre sua prática, impedindo que esta constitua fonte de conhecimento e se estabeleça continuidade com a teoria. Constata-se, mais uma vez, inadequação nas relações entre prática e teoria.

Não é possível estabelecer uma tendência quanto à qualidade das relações entre teoria e prática nos trabalhos-piloto por causa da imprecisão ou falta de detalhamento dos relatos. Independentemente dessa qualidade, os alunos, de modo geral, assumem participação mais ativa e também demonstram maior interesse.

(...) com a evidente melhora na participação dos alunos, pode-se constatar que o professor nunca foi tão solicitado a resolver questões, nunca houve tanta participação dos alunos e nunca houve tanta leitura adicional colocada à disposição dos alunos.

Retomando a análise em seu conjunto, constata-se que o interesse generalizado dos participantes pela maior participação do aluno na própria aprendizagem se concretiza na aplicação do trabalho piloto, em que os respectivos alunos demonstraram interesse por vezes além das expectativas dos participantes. Nem sempre, porém, essa participação implica relações adequadas entre teoria e prática.

Em contrapartida, há diversos relatos que explicitam construção de conhecimentos pelo aluno a partir da própria experiência, situando-se o aluno como pesquisador e o participante enquanto orientador. Em tais situações, a prática do aluno constitui fonte de conhecimento em condições de ser teorizada.

\section{Considerações Finais}

O ponto de partida e de recorrência no CE sempre disponível para acesso à teoria é o trabalho pedagógico do participante. De fato, o trabalho pedagógico é matéria-prima do curso e vai sofrendo transformações à medida que o participante reflete sobre ele, confronta-o com a teoria oferecida, reformula suas concepções e coloca as novas concepções em prática. Prática e teoria se intercalam, alimentando-se mutuamente no decorrer de todo o curso.

Ao iniciar pela reflexão de sua prática, confrontá-la com a teoria e novamente voltar à prática e à reflexão sobre a prática, o participante vai construindo conhecimento e transformando seu trabalho pedagógico. Ao definir as características da transformação de sua prática, promover essa transformação e refletir sobre ela, o participante vai adquirindo autonomia para seguir aperfeiçoando seu trabalho, mesmo depois de concluir o curso.

O CE mantém a expectativa de que os participantes adotem os mesmos procedimentos com seus alunos. Para atingi-la busca influenciá-los de diversas maneiras. No roteiro do diagnóstico pro- 
põe realização de sondagem, visando identificar conhecimentos prévios, interesses e expectativas dos alunos. No planejamento do trabalho piloto, o participante deve explicitar como estabelecerá relação do conteúdo a ser desenvolvido com os conhecimentos prévios dos alunos, bem como a metodologia que utilizará para que eles possam construir conhecimentos. $\mathrm{Na}$ apresentação do trabalho piloto surgem oportunidades para apontar falhas em sua execução, à luz da metodologia empregada no curso. Ao final do CE, no planejamento integral da disciplina ministrada pelo participante, cada orientador pode contribuir para a crítica desse planejamento.

Em suma, o curso não se limita a transmitir informações ou recomendações sobre uma metodologia de ensino supostamente adequada, mas promove a vivência pelo participante de suas novas concepções educacionais, geradas a partir da reflexão sobre o próprio trabalho pedagógico à luz da teoria oferecida.

Comparados ao CE em foco, os cursos de especialização convencionais demonstram ser muito diferentes. Em primeiro lugar não estabelecem relações com o trabalho pedagógico do participante e sua variedade de ingredientes: concepções e procedimentos de ensino; características do alunado, da instituição educacional e da comunidade envolvida. São cursos organizados para uma clientela supostamente padronizada.

Desvinculados da prática do participante, os cursos convencionais ficam com a alternativa de transmitir uma teoria cuja importância por vezes fica resumida à novidade: é a teoria da moda. Mesmo que se faça a crítica da teoria anterior dominante, supostamente ultrapassada, isto não tem significado para o participante, pois o novo modelo é imposto, da mesma forma que o antigo, porque limitados ao discurso sobre o trabalho pedagógico. A crítica que resulta na substituição de um modelo por outro se dá externa e independentemente da prática do participante.

Não tendo elaborado a reflexão de seu trabalho pedagógico, o participante fica sem instrumentos para analisar criticamente o novo modelo. Talvez seja essa a consequência mais perversa dos cursos de especialização convencionais para professores: mantê-los, embora não propositalmente, na eterna dependência de reciclagem, não lhes oferecendo oportunidade de adquirir autonomia para construir conhecimento, atuar como pesquisadores em sua prática educacional e escolher o próprio caminho.

\section{Referências Bibliográficas}

Amaral I.A.do. 1981. Uma estratégia de implementação para as mudanças propostas no ensino de Geologia. In: Simpósio Nacional sobre o Ensino de Geologia no Brasil 1. 1981 Belo Horizonte. Teses... 1. São Paulo: Soc. Bras. Geol. p. 177-187.

Amaral I.A.do. 1990. A reciclagem e a preparação do professor como agente de mudanças educacionais. In: Simpósio Especialização em Ensino de Geociências no $3^{\circ}$ Grau. 1988 Campinas. Anais... Campinas: UNICAMP. p. 21-22.

Amaral I.A.do. 2013. Raízes da mudança curricular ocorrida em 1973 na USP. In: Interfaces Geociências e Ensino: 40 anos de experiências (19732013), Campinas, SP, 23 e 24 de agosto de 2013. (Apres. Oral).

Amaral I.A.do. 2014. Raízes da mudança curricular ocorrida em 1973 na USP. Terre Didatica, 10(2):(esta edição). URL: http:// www.ige.unicamp.br/terraedidatica/.

Amaral I.A.do, Manfredi S.M., Negrão O.B.M. 1981. A formação do geólogo nas universidades brasileiras: um retrato de duas décadas. Brasília: MEC e Soc. Bras. Geol. 209 p.

Candau V.M., Lelis I.A. 1989. A relação teoria-prática na formação do educador. In: V.M. Candau, org. 1989. Rumo a uma nova didática. Petrópolis: Vozes. p. 49-63.

Carneiro C.D.R., Negrão O.B.M. 1995. Busqueda incessante. Rev. de la Enseñanza de las Ciencias de la Tierra, 3(1):61-62. URL: http://www.raco.cat/ index.php/ECT/article/view/89237/141665. Acesso 18.03 .2010

Carvalho A.M.P.de, Gil-Pérez D. 1993. Formação de professores de ciências. São Paulo: Cortez.

Demo P. 1994. Pesquisa e construção do conhecimento. Rio de Janeiro: Tempo Brasileiro.

Freitas L.C.de. 1991. Organização do trabalho pedagógico. Revista de Estudos, 13 (I):10-17.

Freitas L.C.de. 1995. Crítica da organização do trabalho pedagógico e da didática. Campinas: Papirus. 288p.

Gouveia M.S.F. 1995. Ensino de ciências e formação continuada de professores: algumas considerações históricas. Educação e Filosofia, 17(1):227-257.

Gouveia M.S.F., Negrão O.B.M. 1994. Currículo de especialização em ensino de geociências. Campinas: Unicamp. 95 p.

Moreira A.F.B. 1994. Escola, currículo e a construção do conhecimento. In: Escola Básica. Campinas: Papirus. p. 77-88.

Santos L.L.C.P. 1994. Formação do professor e pedagogia crítica. In: I. Fazenda org. 1994. A pesquisa em educação e as transformações do conhecimento. Campinas: Papirus. p.17-41.

Snyders G. 1988. Alegria na escola. São Paulo: Manole. 284 p. 
Sociedade Brasileira de Geologia (SBG). 1982. Simpósio Nacional Ensino de Geologia no Brasil 1. 1981 Belo Horizonte. Documento Final... São Paulo: SBG. 155p.

Sociedade Brasileira de Geologia (SBG). 1983. Simpósio Nacional Ensino de Geologia no Brasil. Currículo Mínimo, 2. 1982, Salvador. Documento Final... São Paulo: SBG. 73p.

Souza J.A.de. 1974. Pesquisa nacional sobre o mercado de trabalho de geólogos e engenheiros de minas. 2. Belo Horizonte: MEC/DAU/CCPG e UFMG/CEDEPLAR.

Universidade Estadual de Campinas (UNICAMP). 1990. Simpósio Especialização em Ensino de Geociências no $3^{\circ}$ Grau. 1988 Campinas. Anais... Campinas: Unicamp. 178p.

Vazquez A.S.1990. Filosofia da praxis. São Paulo: Paz e Terra. 454p. 